\title{
Strategies on Fostering Cross-cultural Communication Ability of Ethnic Minority College Students in Local Ethnic Institutions
}

\author{
Yuanhui Hu${ }^{1}$ \\ ${ }^{1}$ School of Foreign Language, Sichuan Minzu College, Kangding, Sichuan 626001, China
}

Keywords: local ethnic institutions; ethnic minority college students; cross-cultural communication ability; strategy

\begin{abstract}
This paper analyzes the necessity of fostering cross-cultural communication ability of ethnic minority college students in local institutions and expounds the present situation of minority college students' cross-cultural communication ability cultivation, then puts forward constructive strategies for fostering the minority college students' cross-cultural communication ability from creating a real language communication scene, offering cross-cultural communication courses, building the main teaching model of "learning" and cultivating cultural sharpness of the minority college students.
\end{abstract}

\section{Introduction}

Since the accession to the WTO, cooperation and exchanges between China and other countries in the world have become more frequent. The areas for exchanges and cooperation have gradually moved from the coastal areas to the inland areas and ethnic minority areas. Therefore, the cultural and natural areas of ethnic minorities have also been involved in Chinese and foreign cooperation and exchanges. However, due to insufficient cultural propaganda in ethnic minority areas and the lack of opportunities for intercultural communication among ethnic minorities, cultural shocks often occur among ethnic minority people and foreigners. This requires ethnic minority people not only to understand their own national culture, but also to understand the culture of other countries. Local minority colleges and universities are located in ethnic minority areas, carrying the important task of cultivating talents for the region, and also shoulder the heavy responsibility of inheriting and spreading the cultural traditions of the region. The proportion of ethnic minority students in local colleges for ethnic minorities accounts for a large proportion. Most ethnic minority students stay in the region after graduation and become the backbone of their own economic development and cultural heritage. Therefore, local colleges for nationalities should not only pay attention to the cultivation of the basic knowledge of ethnic minority students, but also pay attention to the cultivation of their awareness and ability in cross-cultural communication so that minority college graduates can better serve the political and economic development of this ethnic minority region after graduation.

\section{The Objective Needs of Ethnic Minority Students in Cross-Cultural Communication Ability Training}

\subsection{The Need for International Exchanges}

Due to the rapid development of science and technology, the scope of international political and economic exchanges and cooperation has become wider and wider, and the fields have become wider and wider. In the past, international cooperation was mainly concentrated in the coastal or port cities. However, almost all the provinces, cities and states in the country now have international cooperation projects. Ethnic minority areas have also been embroiled in the system of international economic and political cooperation without exception and have gradually established trade relations with all countries in the world. To survive and develop in a highly competitive international political and economic system, ethnic minority areas must make full use of international and 
domestic resources to serve the political and economic development of their own people in this region. Ethnic minority college students carry the historic mission of political and economic development for the nation, and for the local people to thrive in this region, minority students must have excellent skills in intercultural communication with outsiders.

\subsection{The Need for the Promotion and Inheritance of Minority Cultures}

Ethnic minority college students play an irreplaceable role as the successors and disseminators of their own national culture in the era of high political and economic cooperation and exchanges. While international exchanges and cooperation are taking place, the cultures of various countries are constantly colliding and merging. While ethnic minority areas communicate with foreign countries, their national culture will also be affected by their own mainstream culture and exotic culture. Due to the influence of mainstream culture and exotic culture, the excellent traditional culture of many ethnic minorities in recent years is gradually being eroded and replaced by mainstream culture and exotic culture. In order to carry forward and continue their own local culture, minority peoples should pay attention to their own national culture from their ideology and actions, inherit their own national culture in an active and proactive manner, and endeavor to publicize it. This will enable ethnic minority cultures to go back to ancient times.

\section{Reasons for the Weak Intercultural Communication Skills of Minority Students in Local Minority Schools}

\subsection{The Insufficient College's Attention}

Local ethnic colleges are mostly located in ethnic areas where traffic is relatively backward and geographic locations are remote. Due to the restrictions on geographical conditions in ethnic areas and the lag between economy and transportation, it is difficult to introduce high-level talents and foreign talents. There are few opportunities to communicate with foreigners. Moreover, local colleges for nationalities pay more attention to the mastery of students' basic skills in language, and they do not pay enough attention to students' practical ability to use language. There is no effective method and measure that can effectively detect students' practical ability in using English. At the same time, as minority students mostly taught in their mother tongue before the junior high school stage, that is, minority languages, some ethnic minority areas only offer English classes when students enter high school. After entering the university, students' English proficiency is also very low. Basically, they are only junior high school students. The college's foreign language requirements for ethnic minority students are also relatively low. Students only need to spell some simple words or master some basic grammar structures to achieve graduation conditions.

\subsection{The Teacher's Teaching Concept Needs to be Updated}

At present, the way in which local minority colleges and universities train minority students to develop cross-cultural communication skills depends mainly on college English teaching, with little or no additional and additional means. However, in order to complete the task of teaching, most of the teachers in the English class only manage their own teaching progress, and seldom follow the requirements of the syllabus, that is, communicative interaction is included in the teaching. According to the layout of the teaching content structure, originally each unit of the College English course had 2 hours of communication practice, and the result was occupied by the teacher to speak English grade questions, and students' communication practice did not fall into place. Some local universities and colleges have set the rate of passing English as the standard for assessing the effectiveness of college English teaching. Therefore, college English teaching has become a task oriented towards passing examinations, and it believes that the ability to develop cross-cultural communication skills is inefficient.

Teachers from many ethnic and local colleges and universities still use traditional lecture-based teaching models. Teachers play an absolute leading role in teaching activities, and students are still passively accepting knowledge. The focus of teaching is still on teaching the basic knowledge of 
language, namely grammar and vocabulary. However, there is a lack of attention to cultural issues, students lack of practical exercises on language, and they are unable to acquire the ability of cross-cultural communication. As a college English teacher at a local college of nationalities, the author found through observation that many students who performed very well in general had almost no problems in pronunciation, grammar, and other basic skills and could not use English to communicate with foreign cultures accurately and fluently. They often use Chinese habits to apply exotic customs, sometimes meaning is correct, and sometimes the meaning is very different, thus affecting the normal conduct of communication. At present, under the situation of college English teaching reform, many universities and teachers have begun to pay attention to the introduction of culture in college English teaching, but there are still many deficiencies in content and methods. [4]

\subsection{Lack of Sensitivity to Cultural Differences}

The keenness of cultural differences is to respond to the students' poor ability to respond to cultural conflicts caused by cultural differences between their own and their own. Due to differences in living habits, religious beliefs, and values among people of all ethnic groups, local cultures also vary greatly. If you do not understand the culture of other countries when communicating with foreigners, you may experience misunderstandings. [5] If Chinese people are more subtle, while people in western countries like Britain and the United States speak more directly, the following example is a misunderstanding caused by differences in the way they speak. If a Chinese buys a beautiful dress, one of her acquaintances in the United States praised and said, "very beautiful," but the Chinese said: "It doesn't look good" to show humility. This makes this a foreign country. Friends can not understand, feel that their level of appreciation is not low, judging errors. The reason for this embarrassing situation is because the two of them do not understand the culture and customs of the other country. They both use their country's way of thinking to see the problem. If you do not understand exotic cultures, do not know the cultural differences between Eastern and Western countries, and no sensitive cultural differences, they will cause misunderstandings and failures in cross-cultural communication.

\section{Training Strategies for Developing Cross-cultural Communicative Competence of Minority Students in Local Ethnic Institutions}

\subsection{Experience the Exotic Culture Atmosphere}

Most college English textbooks nowadays are composed of English language ability training and intercultural communicative competence. Teachers can combine the layout and arrangement of teaching materials with reference teaching hours given by each teaching part of the teaching materials to fully ensure that students have the opportunity to participate. According to the theme of each unit, teachers can arrange some role-playing, class discussion, group training, debate games and other activities. For example, when we learn the word Christmas, the teacher can ask some students to prepare some branches in advance, some students use colored paper to make gifts and some students prepare lanterns, and try to let the students do the production of the Christmas tree so that the students can feel it. The atmosphere of exotic festivals also comprehends the cultural connotation of the word Christmas.

The college English teaching is divided into two parts: language basic training teaching and practical teaching. It implements a weekly " $3+1$ ” teaching model, that is, 3 language basic training classes per week and 1 practical teaching lesson. It is practiced as much as possible. Teaching classes create exotic cultural atmosphere for students. Teachers must observe the original English video through the college English practice course, and ask the students to simulate the scene in the video to perform the performance. This will not only improve the students' practical ability in using English, but also increase their interest in learning English. [5]

\subsection{The Establishment of Cross-Cultural Communication Courses}

Minorities and local colleges and universities should, according to the characteristics of the 
region they live in and the actual situation of ethnic minority students, add more courses that can improve students' intercultural communication skills and improve their ability to adapt to society. For example, the student's English course can be divided into four semesters. The first two semesters can be used for basic English courses, and the latter two semesters are mainly for professional English and practical courses. Teachers should appropriately set up public elective courses that help improve their cross-cultural communication skills based on the current level of English of ethnic minority students. At the same time, the teaching content should be reduced and supplemented according to the English language ability of ethnic minority students. The content commonly used in cross-cultural communication should focus on explaining its background knowledge, introduce cultural customs and differences, and thus strengthen the conscious use of minority students.

\subsection{Improve Students' Participation in Teaching}

Traditional teaching activities overemphasize the status and role of teachers. Teachers are the center of the whole class, constantly inculcate and dump knowledge, and rarely stop to understand students' acceptance and understanding. Students are only participants in teaching activities and recipients of knowledge. The teaching model is still a model of old-fashioned single-passed knowledge, and students lack opportunities and motivation to actively participate in teaching activities. Teachers should consciously guide students to understand and accumulate the expression laws, characteristics and methods of English language use, make full use of modern educational facilities and means, allow students to participate in teaching activities, students become the main body of teaching activities, and teachers act as guides. Roles, give full play to the imagination and enthusiasm of students, guide students to overcome obstacles of different cultural differences, thereby improving students' ability to switch to two languages, as much as possible to allow them to experience the fun of learning.

\subsection{Cultivating Minority Students' Sensitivity to Different Cultures [5]}

Ethnic minority students only fully understand the differences between their own culture and exotic cultures, and encourage minority students to actively study and understand exotic cultures and improve their cross-cultural awareness and ability. Minority students must first understand their own national culture, understand the way of thinking and values of people in foreign countries, and gradually cultivate the sensitivity of ethnic minority students to cultural differences so that they can better understand the difference between their own culture and exotic culture, and enhance the Cultural awareness and mitigation of cultural shocks brought about by cross-cultural communication.

According to the overall level and individual differences of the students in the class, teachers are required to read the appropriate amount of foreign literary works according to their actual situation each semester, and let each classmate share the main contents and experience of the works they read. Because literary works can truly and accurately reflect the cultural background at that time and reflect the local people's history, culture, customs, values, religious beliefs, and aesthetic standards, reading literary works enables ethnic minority students to have a deep understanding of the differences between exotic cultures and native cultures. Understanding and understanding will help increase the sensitivity of ethnic minority students to different cultures. For example, Pride and Prejudice, Wuthering Heights, and Jane Eyre not only enabled students to understand the cultural background of foreign countries, but also understood their national personalities and spiritual qualities, and thus their understanding of their own culture.

\section{References}

[1] Li Zhiyuan. Research on Cross-cultural Communication Consciousness and Multicultural Education of Ethnic Minority High-level Talents[J]. Journal of Hubei Institute for Nationalities, 2010(3):28. 
[2] Zhang Jingying. Exploration of teaching reform of college English major based on dialogue theory[D]. Master degree thesis of Nanjing Normal University. 2013.

[3] Zhang Dongmei. Investigation and Research on the Current Situation of Cross-Cultural Teaching in the English Classes of Middle Schools in the Tibet Autonomous Region under the New Curriculum Reform [D]. Master's Dissertation of Tibet University. 2013.

[4] Qi Daorong, Chen Zhe. On the Establishment of Non-English Major Cross-cultural Communication Curriculum[J]. Education and Occupation, 2012(6):139.

[5] Fan Xiying, Zhou Ronghui. Research on Sensitivity and Tolerance of Cultural Difference[J]. Journal of Panzhihua University, 2007(2):52. 